\title{
Lifting Force to Pull the Trapped Child Out of a Narrow Borewell and Scope of Space to Go Below the Trapped Child
}

\author{
Ravi Patel, Lavesh Khabiya, Mukesh Kumar Gupta, Nilesh Kulkarni, Mohsin Khan
}

\begin{abstract}
Since many years, the cases of small children accidentally falling into the uncovered borewell holes are observed in India. In a general procedure, the rescue teams dig an L-shaped hole, parallel to the borewell, to reach the child at the required depth, or tie the hands of the child and try to pull him out. The former method is more challenging and time-consuming if the child is stuck at a depth of more than a hundred feet as they have to cut through rocky soil; while, the second procedure can cause injury to the child. The given paper analyses the position of a child trapped in a narrow borewell. Using the conservation of energy and the reaction forces by the borewell walls on the child, $a$ mathematical expression is derived to calculate the lifting force that will be required to pull out the baby from the same hole (no parallel digging). The paper also calculates the force to insert equipment that can create space around the child without causing any injury to him. This scope of space can be used to go below the child to generate a pushing force for the rescue activity.

Keywords: borewell, borewell accidents, borewell rescue robot, life-saving robot, lifting force calculation, method to rescue
\end{abstract}

\section{INTRODUCTION}

Despite strict government rules against open borewell holes, the cases of children falling into these holes are observed in India. Often, the child trapped in borewell is unable to move his body parts, which makes the role of rescue team crucial in saving the life of the child without causing any injury to him.

The first of the two recent cases in India took place on 25th October 2019 when a boy named Sujith Wilson fell into the borewell in Nadukattupatti village in Tamil Nadu [13]. The child was initially struck at a depth of 26 feet, from where he slipped and got locked at 88 feet below the ground [Fig. 1]. The process of parallel digging to rescue the child became more difficult due to the presence of rocky soil after 80 feet. The child couldn't survive after 80 hours of struggle.

Revised Manuscript Received on April 11, 2020.

* Correspondence Author

Ravi Patel*, Dept. of Mechanical, Medi-caps University, Indore, India. Email: ravi.patel@medicaps.ac.in

Lavesh Khabiya, Dept. of Mechanical, Medi-caps University, Indore, India. Email: khabiyalavesh@gmail.com

Mukesh Kumar Gupta, Dept. of Mechanical, Medi-caps University, Indore, India. Email: guptamukesh281998@gmail.com

Nilesh Kulkarni, Dept. of Mechanical, Medi-caps University, Indore, India. Email: nileshkulkarni154@gmail.com

Mohsin Khan, Soft Tech Solutions, Indore, India. Email: mohsinarakhan@gmail.com

(C) The Authors. Published by Blue Eyes Intelligence Engineering and Sciences Publication (BEIESP). This is an open access article under the CC BY-NC-ND license (http://creativecommons.org/licenses/by-nc-nd/4.0/)
In the second case that occurred on 6th June 2019 in Sangrur, Punjab where a two-year-old toddler, Fatehvir Singh, fell into a 7" borewell and stuck at depth of 150 feet [14]. In the initial 1.5 hours of the rescue operation, the rescue team had successfully tied the hand of the trapped child using hook and clamp [Fig. 2]. However, they were only able to pull the baby out of the hole after 110 hours. Later, he was declared dead in the hospital.

In the latter case, due to the higher force requirement, the rescue team couldn't pull the child out of the hole, even though his hands were tied. The lifting force, thus used, could have caused muscle tear or ligament fracture.

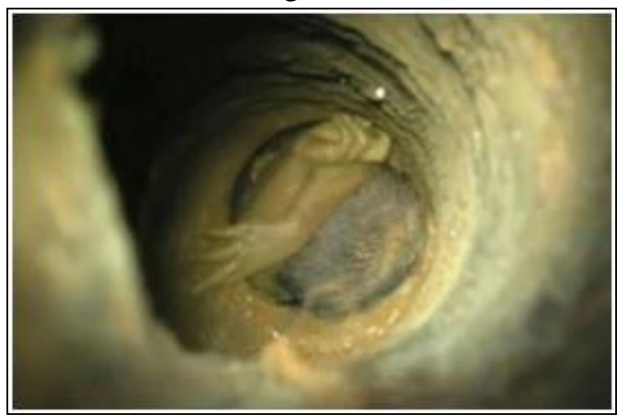

Fig. 1. Recent borewell accident (Tamil Nadu) [16]

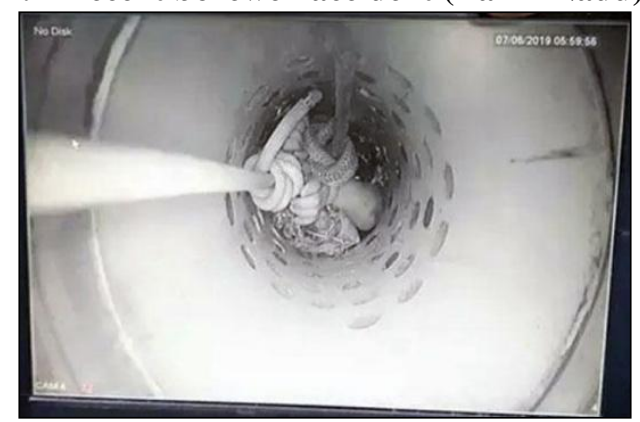

Fig. 2. Recent borewell accident (Punjab) [15]

\section{A. Literature Review}

In their paper, O. Tatar \& D. Mandru proposed an in-pipe modular robotic system adaptable to the inner diameter of pipes for its inspection [10]. K. P. Sridhar proposed a life-saving robot in which he used a grasper to hold the shoulder or wrist of the child. He used a blower to supply fresh air and determined the depth of bore through CCTV cameras [9].

P. Kaur, et. al. suggested a robotic design having three-legged parallelogram structure, which can be adjusted

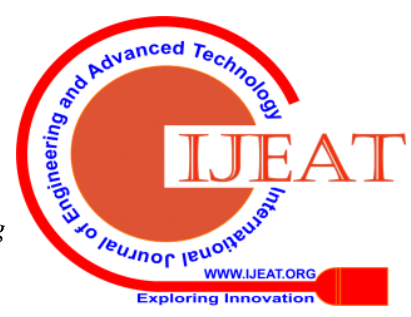


according to the pipeline parameter. They also added gripper, camera, switch-pad in their system [6].

S. Simon, et. al. proposed a borewell rescue robot and monitoring system which can help in the rescue of the child from the borewell [5]. Manjari M V et. al. proposed a model with two layers of safety to prevent the child from slipping further. They used a robotic arm at top and airbag at the bottom with metallic plates on the side to provide support to the child [12].

D. F. Huelke studied the growth and development of the infant and child. He emphasized on their structural difference with adults, which are critical to the design for protection against impact forces [11]. M. Bastir et. al. studied the growth of the thoracic skeleton from the infants till adults morphologically [8].

\section{B. Problem Statement \& Objective}

Rescuing the child trapped in borewell is a very challenging task as every case is unique and requires different approach and handling. In our study, we have used a camera to determine the position of a child. A case is considered in which a baby is trapped in a narrow hole, 7" wide, where the hands of the child are over his head, and the child is stuck with a high compression force on his chest and wings [Fig. 3].

For the above case, in this paper, we have performed a lifting force calculation that can be used to pull the baby out of the hole. This value, being very large numerically, can still cause injury to the child if he is pulled up by simply locking his hands using a hook/clamp or knot in the rope. Hence, it becomes necessary to push the baby up, giving thrust from the bottom of the child.

Also, a fork can be inserted to create space around the child through which the rescue equipment can be sent below him to provide the required thrust. Calculation of force with which this fork can be inserted is also done in this paper.

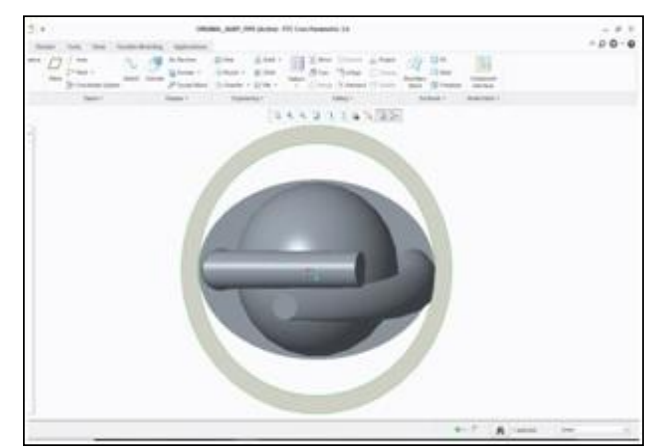

Fig. 3. Proposed position of the child in borewell

\section{PROPOSED METHOD OF RESCUE}

\section{A. Steps to be followed}

1) Use the camera to judge the position of the child.

2) Provide oxygen supply.

3) Tie the hands of the child using a rope and handcuff them.

4) Send thin, hollow forks from the gaps in front and back of the child to explore space to go below the child.

5) Send a camera from one fork to observe the lower body.

6) Perform the rescue activity from the bottom of the baby.

To tie hands of a child, a simple servo motor-based joints robotic arm is used with a gripper to lock the wrist by the handcuffs, which are connected and tied to a long rope that is in control of rescue team.

\section{B. General Arrangement of Rescue Robot and Its Components}

The general arrangement of the robotic arm of this rescue robot is shown in Fig. 4. It has the following components: a Robotic Arm attached to the Robot body, Hand cuff with rope, Camera, and an Oxygen Supply System. Table I provides the design specifications for this robotic arm.

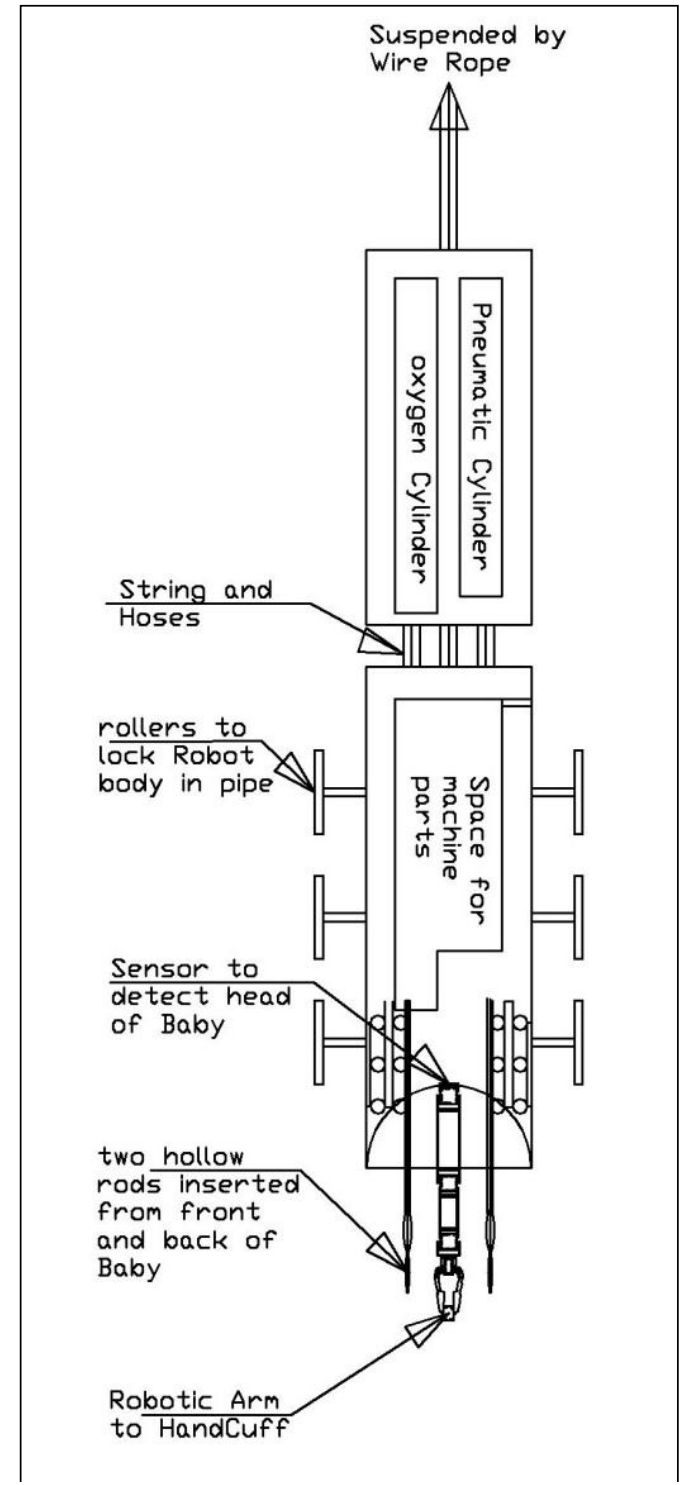

Fig. 4. General Arrangement of Rescue Robot

Table- I: Design Specifications of Robotic Arm

\begin{tabular}{|c|c|c|}
\hline S. No. & Specification & Description \\
\hline 1 & DC Motor & High torque motor of $12 \mathrm{~V}$ \\
\hline 2 & Weight of Child & $10-15 \mathrm{~kg}$ \\
\hline 3 & $\begin{array}{l}\text { Maximum Lifting } \\
\text { force }\end{array}$ & $\begin{array}{l}\text { May vary from 1-20 times the } \\
\text { child weight }\end{array}$ \\
\hline 4 & Bore diameter & $7-18$ inch \\
\hline 5 & Bore Depth & $\begin{array}{l}\text { Any depth (expected shallow } \\
\text { depth say } 150 \text { feet for wireless } \\
\text { signals) }\end{array}$ \\
\hline 6 & Robot Shape & Long , Cylindrical \\
\hline 7 & Oxygen Cylinder & 1.5-3 liters Capacity \\
\hline 8 & Diameter of Hose Pipe & $0.5-1.5$ inch \\
\hline
\end{tabular}




\section{CALCULATION OF LIFTING FORCE (FL)}

When two bullets are simultaneously fired from identical guns on two different wooden blocks (soft and hard), the penetration in soft wood is more as compared to hard wood. If we estimate the force required to pull the bullet out, it is lesser in soft wood as compared to the large force required to pull the penetrated bullet from the hard wood, even though the depth of penetration is less in hard wood.

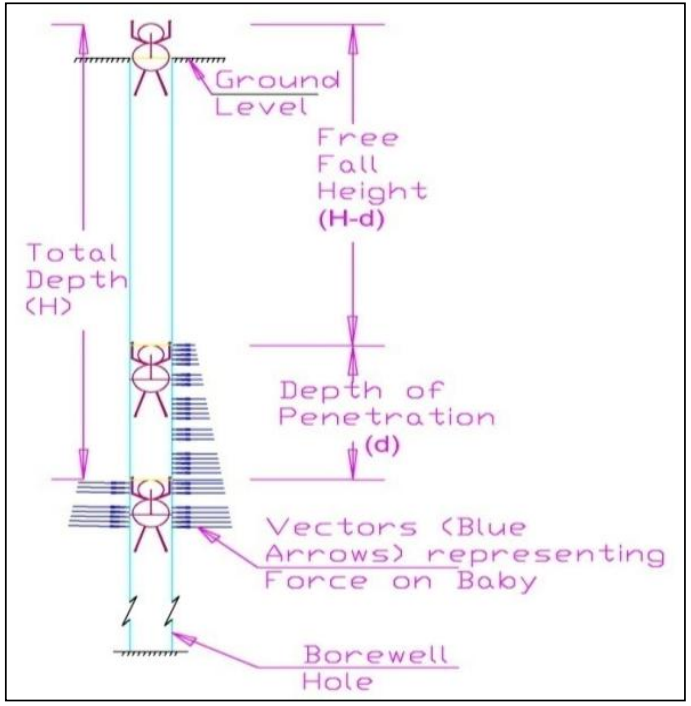

Fig. 5. Depiction of Baby in Hole with depth $\mathrm{H}-\mathrm{d}$ and d

Similarly, in the borewell accidents, for the baby who is stuck at a depth of $\mathbf{H}$ in the ground, it is assumed that he has fallen freely to a depth of $\mathbf{H}$-d. During the free fall, the child has gained kinetic energy that even allows him to pass through a comparatively smaller hole, and due to friction, the baby has finally come to rest. This distance travelled after the free fall till the child came at rest is called Depth of Penetration, d, as shown in Fig. 5.

When the value of free fall height is more (i.e. $d$ is small), it will be similar to the case of hard wood, where high magnitude of force will be required to pull the baby out of the borewell. However, analogous to the case of soft wood, if the Depth of Penetration, d, is large (i.e. H-d is small), the force required to pull the baby out will be lesser as compared to the former case, as in the case of soft wood. The graph in Fig. 6 explains the force of lifting the baby trapped in borewell.

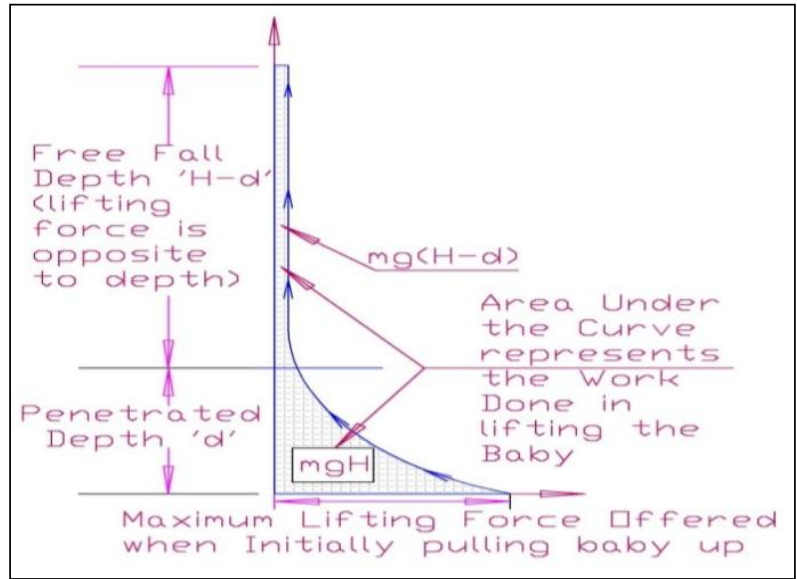

Fig. 6. Lifting Force versus Displacement of Baby

To simplify the calculations, following assumptions have been made in the derivation of the lifting force.

1) The energy absorbed by the baby due to impact while falling is neglected.

2) The drag of air is negligible.

3) The reaction force varies uniformly after the free fall height i.e. from $\mathbf{H}$-d till depth d, i.e. the pipe converges gradually and linearly increases the force of compression on the child during the depth $\mathbf{d}$.

4) The coefficient of friction ' $\mu$ ' for the child and pipe is same throughout the length of $\mathbf{d}$.

5)Kinetic energy is only absorbed in friction offered during the depth $\mathbf{d}$.

During free fall of $\mathbf{H}$-d depth from the ground level, the baby losses its potential energy to gain kinetic energy. This kinetic energy is absorbed in the friction, and eventually, the child gets stuck at depth $\mathbf{d}$, acquiring a total depth of $\mathbf{H}$ with respect to ground level. Hence, the total energy absorbed is mg(H-d) + mgd.

Total Work Done (W) in lifting the child for $\mathbf{d}$ depth is equal to $\mathbf{m g}(\mathbf{H}-\mathbf{d})$, which is absorbed in resisting friction during same depth 'd'.

At any instant, let ' $x$ ' be the total distance through which baby is raised from the trapped position, so the work done in moving ' $\mathrm{dx}$ ' length against high frictional force will be,

$\mathbf{M g H}$ - $\mathbf{m g x}=\mathbf{2} \int \boldsymbol{\mu} \mathbf{R}_{\mathbf{0}} \mathrm{dx}$

The above equation states that the energy absorbed in friction while getting retarded to ' $\mathrm{d}$ ' depth is equal to the work done against friction while, pulling baby for same d depth. Hence, Work Done for pulling the baby out for distance $\mathbf{d}$ will be,

$$
\text { mgH }- \text { mgd }=2 \int \mu R_{0} d x
$$

where,

$\mathrm{R}_{\mathrm{o}}=$ Reaction Force of wall on baby at any instance

$\mathrm{R}=$ Maximum Reaction Force when lifting the baby

$\mu=$ Coefficient of Friction.

$2 \mu R_{o}=$ Total Friction Force (on both the shoulders of the baby due to walls of borewell)

The maximum reaction force ' $R$ ' on baby, reduces to zero linearly after the baby is pulled out for distance $\mathbf{d}$. So,

$$
\mathbf{R}_{\mathbf{0}}=\mathbf{R}(\mathbf{d}-\mathbf{x}) / \mathbf{d}
$$

Work Done $=$ mgH - mgd $=2 \int \mu \frac{R}{d}(d-x) d x$

where integration limits are from 0 to $\mathrm{d}$,

$$
\begin{aligned}
& \operatorname{Mg}(\mathrm{H}-\mathrm{d})=2 \int_{0}^{d} \mu\left\{\frac{R}{d}(d-x) d x\right\} \\
& \operatorname{mg}(\mathrm{H}-\mathrm{d})=2 \int_{0}^{d} \mu \frac{R}{d}\{(d-x) d x\}
\end{aligned}
$$

By integration,

$$
\begin{gathered}
\mathrm{mg}(\mathrm{H}-\mathrm{d})=\mu R d \\
\mathbf{R}=\frac{m g(H-d)}{\mu d}
\end{gathered}
$$

Hence, maximum force required to lift up child against friction will be,

$$
\begin{gathered}
\mathrm{F}_{\mathrm{L}}=2 \mu R \\
{ }^{* *} \mathbf{F}_{\mathbf{L}}=\frac{2 m g(H-d)}{d}
\end{gathered}
$$

**This lifting force $\mathrm{F}_{\mathrm{L}}$ is additional to the weight of the baby.

Published By:

Blue Eyes Intelligence Engineering

\& Sciences Publication

DOI: 10.35940/ijeat.D7713.049420

Journal Website: www.ijeat or

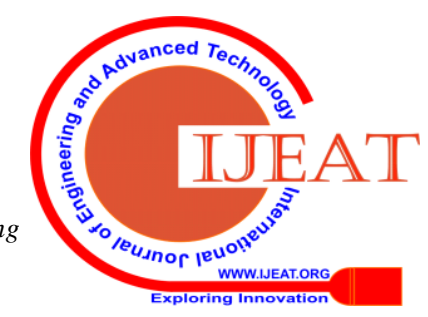




\section{SCOPE OF SPACE TO GO BELOW THE CHILD}

\section{A. Understanding the Child's Position}

The borewell acts like a circular wall around the child and compresses the baby. However, as seen from top view, the shape of the child's rib cage is elliptical. This generates the possibility to make space in the front and back of the child as shown in the Fig. 7.

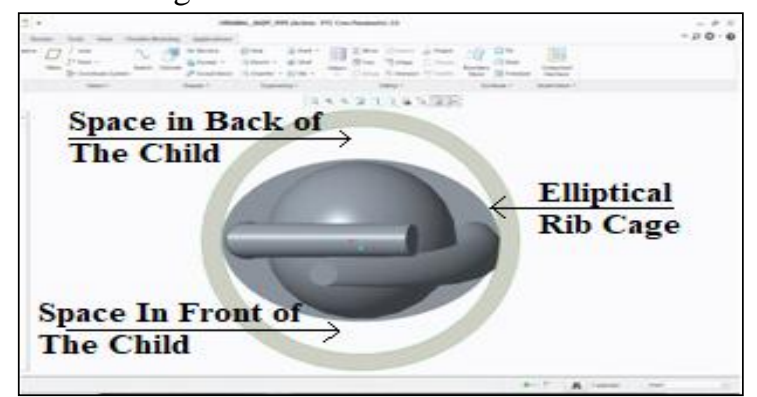

Fig. 7. Elliptical Rib Cage \& The Scope of Space

The rib cage of a baby has elastic nature. No injury will be caused to the thoracic organs of the baby when the rib cage is compressed up to $25 \mathrm{~mm}$ on chest. Also, the rib cage can be assumed as an ellipse whose average major and minor axis is $180 \mathrm{~mm}$ by $130 \mathrm{~mm}$ respectively.Hence, the total gap measured diametrically from the front to back of the baby (along the minor axis of ellipse) is $50 \mathrm{~mm}$.

\section{B. Robotic Fork Inserted from Top in the Space in the Front and Back of the Child}

A fork with robotic arm, as shown in Fig. 8, can be inserted in the space in the front and back of the child [Fig. 9]. The fork is of the semicircular cross-section having a detachable semi-conical base [Fig. 10] pointed towards the walls of the borewall thus preventing the child to cause any injury by fork.

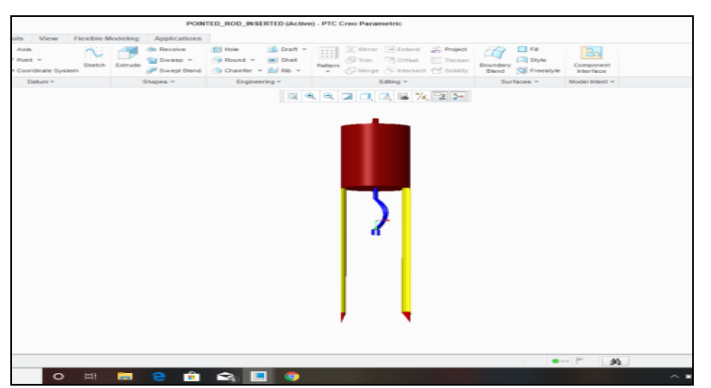

Fig. 8. Fork to Insert in Space in Front and Back of Baby

The conical tip is restrained while pushing down the fork due to compression at the junction. The curve shape of the fork is kept towards the baby to pressurize and push the chest and the back of baby to create the required space, simultaneously sliding down relative to the baby. This creates a path for the rescue equipment to go below the baby through space in his front and back.

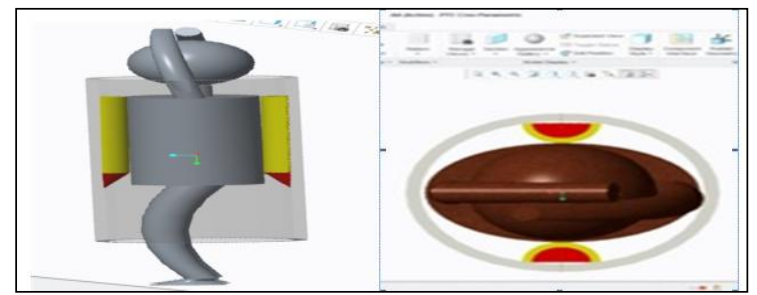

Fig. 9. Assumed Position of Baby with Inserted Fork

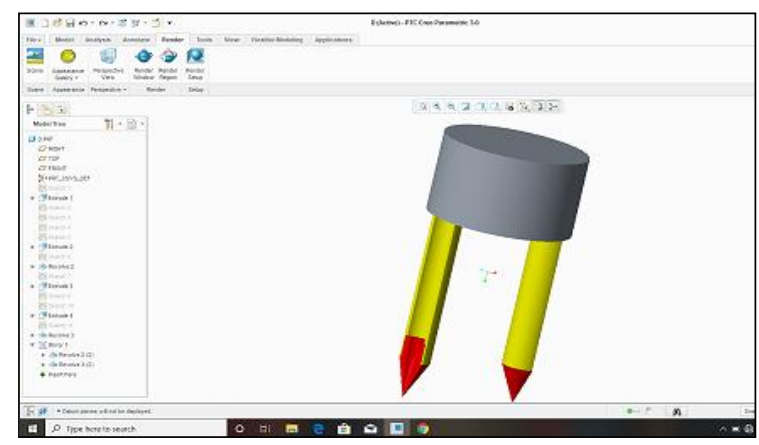

Fig. 10. Semi-circular, cross-section of Fork having a detachable semi-conical base

When any equipment reached the base of the hollow space in the fork, the semi- circular cone is ejected in the borewell. This results in the detachment of this conical part, resulting in an open space toward the bottom of the borewell as shown in Fig. 11.

Rescue robot or manipulator can perform activities related to the rescue from the bottom of the child. For this, a $30 \mathrm{~mm}$ diameter cylindrical manipulator can be allowed to pass and reach below the legs of the child without causing any injury to the child.

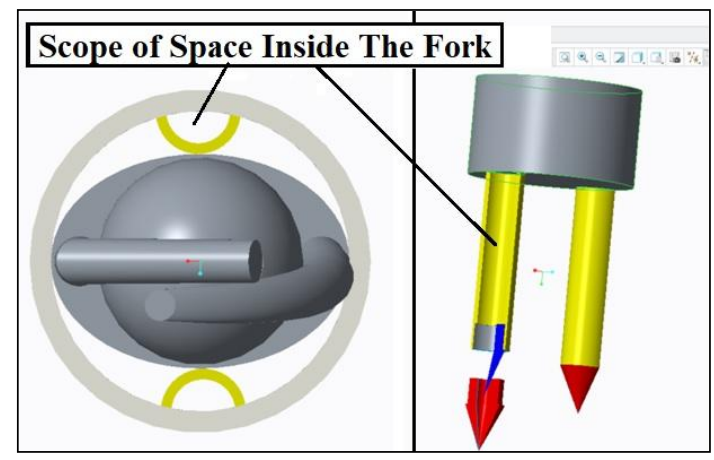

Fig. 11. Through Space near the baby, the Detachment of Conical Tips.

\section{Calculation of Force to Insert Fork}

As discussed above, the child's rib cage along with the skin and layer of fat can be considered as an ellipse whose major axis is equal to the size of the borewell $(180 \mathrm{~mm})$ and the minor axis is $130 \mathrm{~mm}$. Hence, the circumference of the chest is roughly about $500 \mathrm{~mm}$. While passing these forks down with the force $\mathbf{F}^{*}$, the hands of the child are to be pulled up with a force $\mathbf{F}$ which is calculated from the equations that are obtained from the free body diagram of the Fork and the Child (Fig. 12 \& Fig. 13).

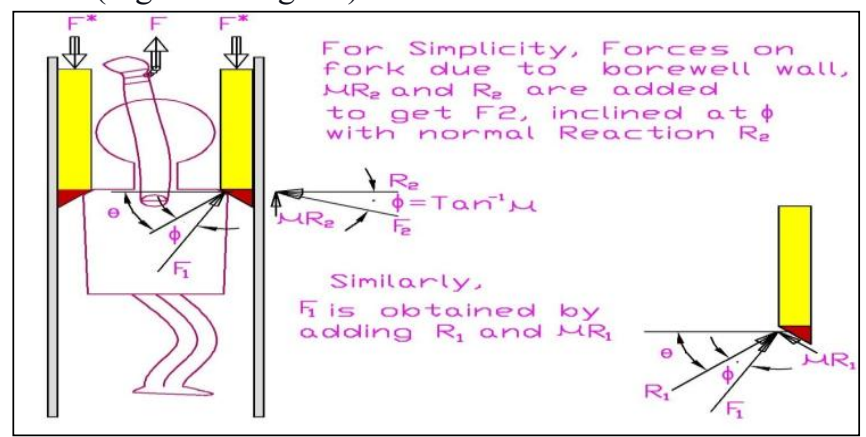

Fig. 12. Forces Acting During the Insertion of the Fork

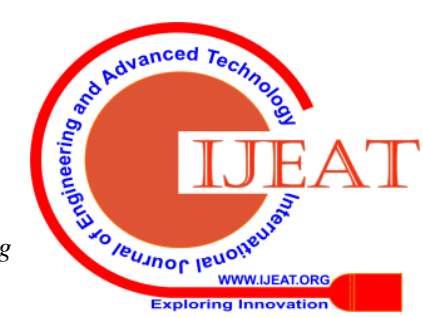


In Fig. 12, $\theta$ is the semi-cone angle of the tip of the fork and $\Phi$ is friction angle calculated as $\tan ^{-1} \mu$. Also, $\mathbf{R}_{\mathbf{1}}$ and $\mathbf{R}_{\mathbf{2}}$ are the Reaction forces acting on fork due to the child and the borewell walls respectively. Also, friction forces are acting along with the reaction forces at the points of contacts, which are represented by $\boldsymbol{\mu} \mathbf{R}_{\mathbf{1}}$ and $\boldsymbol{\mu} \mathbf{R}_{\mathbf{2}}$. For simplicity, these forces are combined to get $\mathbf{F}_{\mathbf{1}}$ and $\mathbf{F}_{\mathbf{2}}$

From Fig. 13, the free body diagrams give the following relations for the static equilibrium of the fork and the baby in the borewell.

$$
\frac{F^{*}}{\sin [180-(\theta+2 \emptyset)]}=\frac{F_{1}}{\sin (90+\emptyset)}=\frac{F_{2}}{\sin [180-(\theta+2 \varnothing)]} \text {, and }
$$

$$
\frac{2 \mu R+F-m g}{\sin [180-2(\theta+\emptyset)]}=\frac{F_{1}}{\sin 90+(\theta+\emptyset)}
$$

On modifying the above two relations, we get,

$$
\begin{gathered}
\frac{F^{*}}{\sin (\theta+2 \emptyset)}=\frac{F_{1}}{\cos \emptyset}=\frac{F_{2}}{\sin (\theta+2 \emptyset)} \\
\frac{2 \mu R+F-m g}{\sin 2(\theta+\emptyset)}=\frac{F_{1}}{\cos (\theta+\emptyset)}
\end{gathered}
$$

For ease of calculation, the coefficient of friction $\mu$ is assumed to be same for the baby and the fork, as well as, the fork and the borewell walls. Using the above two relations where the $\mathbf{F}_{\mathbf{1}}$ is the reaction of rib cage on the fork (as per CPR guidelines for children below 12 months, 15 pounds of force can be applied for one inch chest compression without causing any injury to the rib cage under elastic deformation), we can find $\mathbf{F}^{*}$ which is the required pushing force on the fork for insertion. Please note that the effect of the weight of the fork is not considered to derive this relation. If the weight of the fork is to be considered, it needs to be subtracted from $\mathrm{F}^{*}$. By using the second relation, where $\mathbf{m g}$ is the weight of the child, $2 \mu \mathbf{R}$ is the total frictional force acting on shoulders and wings of the child due to borewell walls. We can find the force $\mathbf{F}$ by which the handcuffs can pull the baby upwards so as to insert the fork without letting the child to slip further. Here $2 \mu \mathbf{R}$ can be obtained from the derivation done in section III.

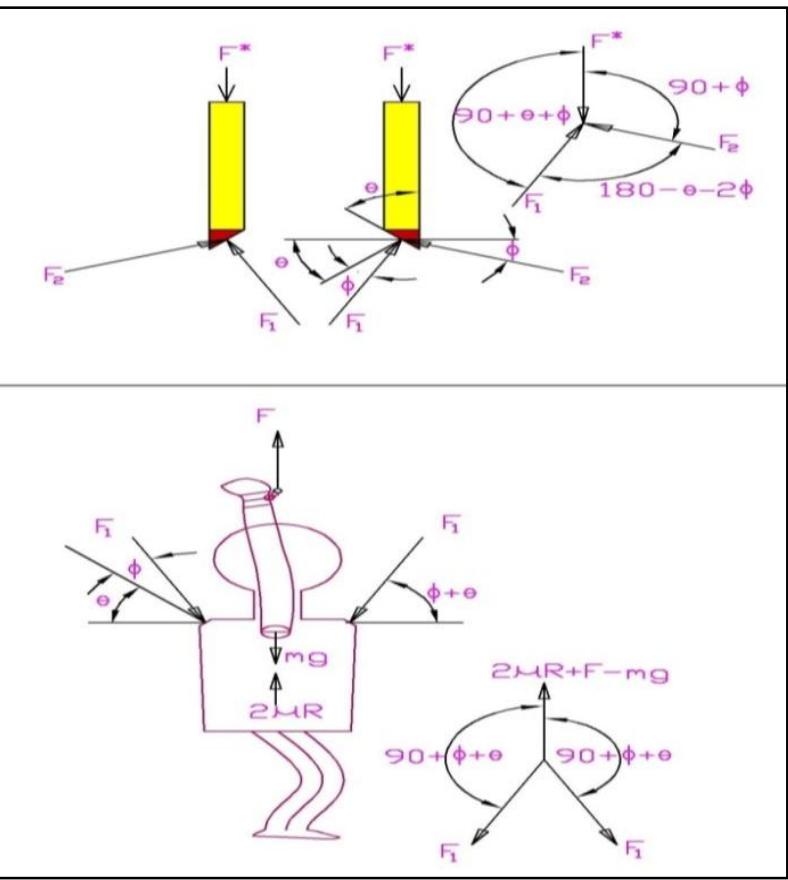

Fig. 13. Free body diagrams of the Fork and the Child

\section{RESULTS}

The proposed system can rescue the child from borewell in minimum cost and minimum time. The different values of Lifting Force for given values of $\mathbf{H}$ and $\mathbf{d}$ are given in Table II from the relations derived in Section III.

Table II. Maximum Lifting Force

\begin{tabular}{|c|c|c|c|}
\hline $\begin{array}{c}\text { Weight } \\
\text { (kg) }\end{array}$ & $\begin{array}{c}\text { Height (H) } \\
\text { (feet) }\end{array}$ & $\begin{array}{c}\text { Depth of } \\
\text { Penetration (d) } \\
\text { (feet) }\end{array}$ & $\begin{array}{c}\text { *Lifting Force (F } \mathbf{F}_{\mathbf{L}} \text { ) } \\
\text { (kgf) }\end{array}$ \\
\hline 12 & 30 & 5 & 120 \\
\hline 12 & 30 & 10 & 48 \\
\hline 12 & 30 & 15 & 24 \\
\hline 12 & 30 & 20 & 12 \\
\hline
\end{tabular}

*Note: Add the weight of the baby to calculate the final value of force required to pull the baby out of the borewell hole excluding the weight of the robotic equipment.

Table III. Pushing Force Required to Insert Fork

\begin{tabular}{|c|l|c|}
\hline S. No. & \multicolumn{1}{|c|}{ Parameters } & Values \\
\hline 1 & Fork Tip Semi Cone Angle $(\theta)$ & $30^{\circ}$ \\
\hline 2 & Friction angle (Ø) for $\mu=0.36$ & $20^{\circ}$ \\
\hline 3 & $\begin{array}{l}\text { Force on ribs for } 25 \mathrm{~mm} \text { chest } \\
\text { compression } \mathbf{F}_{1} \text { (in kgf) }\end{array}$ & 4.0 \\
\hline 4 & $\begin{array}{l}\text { Calculated Pushing force on } \\
\text { fork } \mathbf{F}^{*} \text { (in kgf) }\end{array}$ & 4.75 \\
\hline 5 & $\begin{array}{l}\text { Calculated Pulling force } \mathbf{F} \text { on } \\
\text { handcuffF (kgf) }\end{array}$ & $6.13-2 \mu \mathrm{R}+$ Baby Weight \\
\hline
\end{tabular}

The force required to insert the fork such that no injury is caused to the baby is calculated using relation from Section IV C.

\section{CONCLUSION}

The following conclusions can be made from the Table II. 1) The force required to lift the child out of the hole is multiple times of body weight of the child in general.

2) If the free fall height $\mathbf{H}$-d is large and further retarded depth $\mathbf{d}$ is small, the force to pull the baby out of the hole is very large, which make the rescue task more challenging

3) If the baby did not fall freely for long distance and travelled more rsisting to friction, then $\mathbf{H}-\mathbf{d}$ is small as compared to $\mathbf{d}$ and the lifting force is almost equal to the weight of the child.

From the derived relations, we have used some value of parameter mentioned in the Table III, it has been concluded that more is the friction force $(2 \mu \mathbf{R})$ between the borewell walls and the child, lesser is the value of the force $\mathbf{F}$ required to pull the child up by handcuffs when the fork is inserted into the hole with force $\mathbf{F}^{*}$. This enhances the feasibility of rescuing the child using the given method.

A scope of space is created in the front and the back of the child that can be used to reach below him to perform rescue activities. In order to send the equipment below the child, the two semi-circular space of diameter 50mm (front and back) through the hollow portion of the fork can be used.

\section{FUTURE SCOPE}

The following improvements can be made in the given rescue robot that will increase the performance and usability of the robot. 
1) An adaptive equipment or a robotic manipulator can be designed which can reach to the bottom of the child from the scope of space as shown in this paper. This will assist in lifting the child from the bottom.

2) The equipment to grab the baby from the lowermost part and pushing up can be developed to aid the rescue of the baby.

3) Sensors and actuators can be installed for saving time in operation and improve functioning of robot.

4) To counter the high lifting force, a system to provide thrust to the child can be designed in future.

\section{REFERENCES}

1. P. K. Nayak \& S. Saini, “An Audit Paper on Borewell Robot,” IJERT, Vol. 8, Issue 5, May 2019, pp. 401-404.

2. P. Thangaraj \& S. Gavaskar, "Borewell Rescue to Child Using IOT Techniques: A Survey," IJRAT, Vol. 6, Issue 10, October 2018, pp. 2744-2752.

3. S. Prakash, K. N. Devi, J. Naveetha, V. Vasanth, and, V. Vishnushree, "Smart Bore well Child Rescue System", IRJET, Vol. 4, Issue 3, March 2017, pp. 358-362

4. A. Francis, D. Anbalagan, and C. Balachandran, "Child Rescue from Borewells”, SAJET, Vol. 3, Issue. 3, March 2017, pp. 63-70.

5. S. Simon, M. Jose, M. J. Gogy, K. D. Vismaya, and S. Mukundan, "Borewell Rescue Robot," IRJET, Vol. 3, Issue 3, March 2016, pp. $140-144$

6. P. Kaur, R. Kaur, and G. Singh, "Pipeline Inspecton and Borewell Rescue Robot," IJRET, Vol. 3, Issue 4, April 2014, pp. 726-729.

7. M. Raj, P. Chakraborty, and G.C. Nandi. (2014, April). Rescue Robotics in Bore well Environment [Online]. Available: https://www.researchgate.net/publication/262974368

8. M. Bastir, D. M. Garcia, W. Recheis, A. Barash, M. Coquerelle, et. al., "Differntial Growth and Development of the Upper and Lower Human Thorax", PLOS ONE, Vol. 8, Issue 9, September 2013.

9. K. P. Sridhar. (2011, June). Life Saving Machine [Online]. Available: https://www.researchgate.net/publication/301694373

10. O. Tatar \& D. Mandru (2009, January). Design of In-Pipe Modular Robotic System, Solid State Phenomena [Online] .Vols. 147-149 (2009) pp. 49-54 https://www.researchgate.net/publication/243762443 Design of In-Pi pe_Modular_Robotic_Systems

11. D. F. Huelke (1998), An Overview of Anatomical Considerations of Infants and Children in the Adult World of Automobile Safety Design [Online]. Available: https://www.ncbi.nlm.nih.gov/pmc/articles/PMC3400202/

12. Manjari MV, Meghana HS, Vijay Kumar M, and Rajesha C. Design and Implementation of Borewell Rescue Robot Using Lab View [Online]. Available: http://www.kscst.iisc.ernet.in/spp/38_series/spp38s/synopsis_exhibitio n/148 38S1474.pdf

13. https://www.ndtv.com/india-news/sujith-wilson-trichy-muddled-rescue -blamed-for-death-of-tamil-nadu-boy-who-fell-in-borewell-2123887

14. https://www.indiatoday.in/india/story/borewell-child-punjab-sangrur-d ead-fall-1546357-2019-06-11

15. https://www.bhaskar.com/punjab/bathinda/news/rescue-operation-for-2 -years-old-fatehveer-singh-at-hid-village-bhagwanpura-01565755.html ?sld seq $=2$

16. https://www.indiatoday.in/india/story/tamil-nadu-2-yr-old-falls-into-25 -feet-deep-borewell-rescue-ops-underway-1613048-2019-10-26

\section{AUTHORS PROFILE}

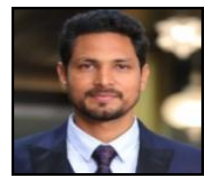

Mr. Ravi Patel, currently working as Assistant Professor in Dept. of Mechanical Engineering, Medi-caps University, Indore, India. He has done M. Tech. in Mechanical (specialization in Design Engineering) from Medi-Caps University, Indore, India and B.E. (Mehanical) from SVCE, Indore, India.

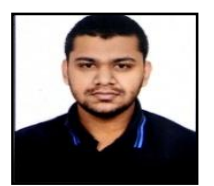

Mr. Lavesh Khabiya, currently pursuing B. Tech (Mecshanical Engineering 2016-2020) at Medi-caps University, Indore, India

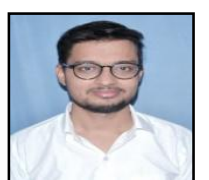

Mr. Mukesh Kumar Gupta currently pursuing B. Tech (Mechanical Engineering 2016-2020) at Medi-caps University, Indore, India

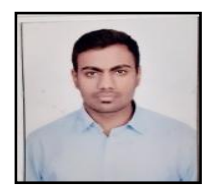

Mr. Nilesh Kulkarni currently pursuing B. Tech (Mechanical Engineering 2016-2020) at Medi-caps University, Indore, India

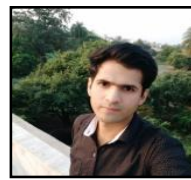

Mr. Mohsin Khan, Owner of Soft Tech Solutions, Indore, India. He has done B. E. in Electronics and Communication Engineering from Astral Institute of Technology and Research Centre

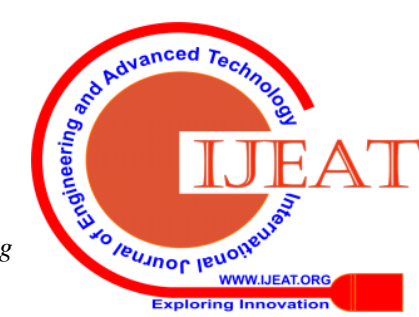

